future would be ill-advised to push for too much change too soon, even if the finance ministry is as culpable as supposed. So what else is to be done?

Luckily, where science and technology are concerned, the machinery for getting a grip on government exists; it needs to be made effective. For many years, Japan has maintained a Council on Science and Technology (CST) which, by including the prime minister, the minister of finance, other relevant ministers and several people from industry and academic life, is a cross between an advisory council and an executive committee of the cabinet (see Nature 359, 579; 1992). One of its weaknesses is that it is regarded as a creature of the education ministry (which means that other ministries regard it with profound suspicion). But a new government could change that, as it could also change the council's over-cumbersome way of working. In short, without fighting the Ministry of Finance headon, a new government in Tokyo could, with a little courage, bring about an overdue reform and ensure that Japan's flair for technical innovation is not dissipated.

That would be beneficial for Japan in many ways. Over several years, a consensus has emerged on the need to strengthen basic research at the universities. Not only academics but industrial associations are saying just that; Japan is beginning to sense a scarcity of skill. Last year, the Council on Science and Technology declared that the budgets in the field should be doubled, but characteristically neglected to say by when that state of grace should be attained.

That is a cause the new government, whatever form it takes, could usefully take up. The issue is literally that of whether Japan can sustain the momentum of the past four decades. The new government it will know that Japan's voters will be watching like hawks to see that its arrival does not make Japan falter. There is little comfort in that for Japan's rivals elsewhere.

\section{The lab of last resort}

The British government should give a better explanation of its decision to manage a public laboratory directly.

QuiTe what the British government hopes will emerge from its decision to take over the direct management of what is now the largest public laboratory in Britain will remain a mystery for some time (see page 369). The Rutherford Appleton Laboratory, itself the residual legatee of many past research programmes, now seems destined to become the only tangible residuum of an age of relative innocence in the administration of research in Britain. The history of the laboratory tells the story.

At the outset, the Rutherford Laboratory was founded (just across the wire fence from the Atomic Energy Research Establishment at Harwell in Oxfordshire) as Britain's premier high-energy physics laboratory. But the proton accelerator called Nimrod was too little and too late. The research councils' commitment to the venture was nevertheless confirmed by the physical transfer to the site of the Radio Research Station, otherwise the Appleton Laboratory, from its previous location at Slough, some 30 miles to the east.

With the passage of time, the laboratory became a provider of research facilities generally to the academic research community. If there was a satellite project to be managed, the laboratory would take it on, as it took on the management of the complicated software project to transfer images of the sky from one academic laboratory to another. Latterly, it has become the chief British source of neutrons for research; when the Daresbury laboratory is merged, the Rutherford Appleton Laboratory (RAL) will be the British source of synchrotron radiation as well.

There is no doubt of the competence of RAL, whose excellent staff have an enviable record of versatility and achievement. The question that seems not to have been asked during the long preparation of the British government's white paper on research is whether there is a need for a laboratory of this kind whose cost is likely to be a substantial fraction, perhaps a third, of what the new research councils are able to spend on research in academic institutions.

If the question had been asked, it might have been answered in ways that would disappoint RAL. For the past quarter of a century, it has not been easy to understand why the support of substantial research projects should always be managed by this central laboratory rather than by their prime movers, the researchers winning financial support for them. True, in fields in which many researchers are active, central support may bring economies, but there are not many of them in Britain. And when one of the complaints against British basic science is that it is not sufficiently in touch with the real world, would it not be an advantage that those who win support for ambitious projects should also have to cut their teeth on their effective management and execution? On the face of things, RAL's present role works against the government's declared intention of making British science more aware of the realities of industrial life.

There are further dangers in the arrangements now planned. RAL is to be self-standing in the sense that it will earn its keep from the reimbursement of the costs of research support provided by the research councils. But what if, for example, under the new pattern of next year and beyond, the research councils commission no research in some of the fields RAL is ready to support? Will the costs of those unrequited services be spread over the costs of research in other fields? Or will RAL become the researcher of last resort when its own people use equipment unwanted by outsiders to throw back the frontiers of ignorance in fields that, of necessity, will be determined historically and not by new foresight methods on which the government is pinning its faith? It will be interesting, in these ambiguous circumstances, to see how the government manages to write its promised "mission statement" for RAL. 